\title{
Middle East respiratory syndrome in Al Ahsa, Saudi Arabia, 2015-18: a lingering epidemic
}

\author{
Hanan AI Shaikh, Balaji Rama Naik, \\ Ahmed Saleh Alsaad, Abdullah Ali Albinsaleh \\ Directorate of Health Affairs, \\ Ministry of Health, \\ Al Ahsa, \\ Kingdom of Saudi Arabia
}

\begin{abstract}
Middle East respiratory syndrome (MERS), an emerging disease with fatal outcomes, has limited information on regional variations and their impact on the control measures. The aim of this study was to describe data on distribution of and possible association of risk factors for the disease and poorer outcomes, and recommendations for better control of the disease. Data were collected for 2015-2018 in Al Ahsa, the largest region (population 1.2 million) in the eastern part of Saudi Arabia.
\end{abstract}

In total, 103 cases were reported during the study period with fever and cough as predominant presenting symptoms. The majority were male, $>50$ years old, and Saudi nationals. One third of patients had comorbid conditions (diabetes and cardiac predominantly). Occupation profiles of the patients varied, with camel owners and security personnel constituting $40 \%$ of the study population.

Inconclusions, older age, nationality, extracorporeal membrane oxygenation (ECMO) treatment, and associated comorbid conditions were found to be probable risk factors for poor outcomes. The mortality rate (59\%) was distinctly higher in patients aged $>60$ years. The study highlights probable risk factors for poor outcomes in MERS patients, and discusses scope for further intervention and better management.

Keywords: Middle East respiratory syndrome, risk factors, mortality, Saudi Arabia

\section{Corresponding Author}

Dr. Balaji Rama Naik;

Infection Control Specialist, Infection Prevention and Control Administration. Directorate of Health Affairs, Al Ahsa, Ministry of Health, Saudi Arabia.

E-mail: drbalajinaik@gmail.com 


\section{Introduction}

Middle East respiratory syndrome (MERS), caused by the MERS-Corona Virus (MERS-CoV), is one of the top 10 emerging diseases listed by the World Health Organization (WHO), based on case fatality rate and transmissibility. MERS has entered the human population because of human contact with infected dromedary camels. ${ }^{1}$

Initial reports of MERS were published in 2012 from Saudi Arabia; research continues to improve scientific understanding of the virus. ${ }^{1,2}$ Globally, outbreaks of MERS have been reported periodically; ${ }^{3}$ smaller regional outbreaks occur, which can develop into epidemics. Understanding these variations in disease presentation will help prevent further outbreaks. Here we describe socio-demographic features of MERS cases in Al Ahsa (population: 1.2 million; largest region in the eastern part of Saudi Arabia) from a fouryear (2015-2018) dataset. ${ }^{4}$

\section{Methods}

Setting: Ministry of Health $(\mathrm{MoH})$ and private health care facilities of Al Ahsa, the largest governorate in the eastern province of Saudi Arabia.

\section{Study design}

Descriptive study based on routinely collected program data. Data collected by Infection Control Administration and the Regional Center for Command and Control (CCC) of Al Ahsa region for 2015 to 2018 for all confirmed cases of MERS Co-V were used; all included MERS cases were treated in hospitals designated by the $\mathrm{MoH}$. Data were extracted from the rapid response team (RRT) reports prepared by RRT members as and when the cases were notified. The key variables included in the study were age, sex, nationality, history of contact with camels, extracorporeal membrane oxygenation (ECMO) treatment, comorbid conditions (Table I). Data were analyzed for socio-demographic characteristics, primary/ secondary status of the cases, presenting complaints, existing comorbidities, time delays during the course of management, presence of pneumonia on chest X-ray, history of contact with camels/ camel products, and patient outcome. The case definition for confirmed cases was as per $\mathrm{MoH}$ regulations. ${ }^{5}$

\section{Statistical Analysis}

Data were analyzed using the EpiData analysis software (Version V2.2.2.185; EpiData Association, Odense, Denmark). Frequencies and proportions were calculated. Differences between groups were compared using Chi square tests and $95 \%$ confidence intervals (Cls). A p-value of $\leq 0.05$ was considered as statistically significant.

\section{Results}

Over a four-year period (2015-2018), 103 confirmed MERS cases were reported. The majority (69\%) were men, median age (inter quartile range - IQR) was 53 years (37.3-63.5), with a higher proportion (58\%) of patients aged $>50$ years. The socio-demographic and clinical characteristics are shown in Table I. The median (IQR) duration from symptom onset to death and from admission to death was 16 days ( 6 to 22 ) and 17 days (8 to 26), respectively.

Bivariate analyses with death as outcome are shown in Table II. Among comorbidities, diabetes mellitus alone or in combination with other diseases was found in 47 (63\%) out of 75 comorbid patients. Ischemic heart disease with or without other conditions was reported in $44 \%$ patients and hypertension was found in $66 \%$ patients. Thirteen patients were smokers and nine had renal issues. There were seven patients with multiple comorbidities. The overall death rate was $46 \%$. Death rate among patients aged 60 years and above was $64 \%$ with the highest rate of $86 \%$ among patients aged more than 80 years. Of the 10 patients on ECMO, nine died during treatment. A high proportion (56\%) of patients who died had a history of contact with camels, but the finding was statistically insignificant $(p=0.14)$.

Fever and cough were the most common presenting symptoms (75\% cases). Other symptoms included shortness of breath (33\%), vomiting (17\%), chest pain (10\%), abdominal pain (8\%), constipation (7\%), and diarrhea (7\%). The job profiles of the patients were: security officer $(20 \%)$, camel owner $(20 \%)$, and the remaining were driver, retired personnel, construction worker, house wife, feed market vendor and nurse. For those who died; the job profiles were: camel owner (30\%), construction worker (15\%) and the rest constituted retired personnel, security officer, feed market vendor, and house wife. 
Table I. Socio-demographic and key clinical characteristics of confirmed Middle East Respiratory Syndrome cases in Al Ahsa, Saudi Arabia (2015-2018).

\begin{tabular}{|c|c|}
\hline Characteristic & MERS $^{*}$ Cases $(\mathrm{N}=103)$ \\
\hline & No (\%) \\
\hline \multicolumn{2}{|l|}{ Age } \\
\hline$<50$ years & $42(41)$ \\
\hline$\geq 50$ years & $61(59)$ \\
\hline \multicolumn{2}{|l|}{ Sex } \\
\hline Male & $75(73)$ \\
\hline Female & $28(27)$ \\
\hline \multicolumn{2}{|l|}{ Nationality } \\
\hline Saudi & $75(73)$ \\
\hline Non-Saudi* $^{* *}$ & $28(27)$ \\
\hline \multicolumn{2}{|l|}{ Type of case } \\
\hline Primary & $36(35)$ \\
\hline Secondary & $61(59)$ \\
\hline Unknown & $6(6)$ \\
\hline \multicolumn{2}{|c|}{ Health care worker } \\
\hline Yes & $19(18)$ \\
\hline No & $84(82)$ \\
\hline \multicolumn{2}{|c|}{ Contact with camel } \\
\hline Yes & $34(33)$ \\
\hline No & $69(67)$ \\
\hline \multicolumn{2}{|c|}{ Contact with human case - probable or confirmed } \\
\hline Yes & $53(52)$ \\
\hline No & $50(48)$ \\
\hline \multicolumn{2}{|c|}{ Associated comorbidity } \\
\hline Yes & $75(73)$ \\
\hline No & $28(27)$ \\
\hline \multicolumn{2}{|c|}{ Patient on ECMO ${ }^{\pi}$} \\
\hline Yes & $10(10)$ \\
\hline No & $93(90)$ \\
\hline \multicolumn{2}{|c|}{ Duration between admission and death (days) } \\
\hline$<7$ days & $17(38)$ \\
\hline$\geq 7$ days & $28(62)$ \\
\hline \multicolumn{2}{|c|}{ Duration between onset of symptoms and death (days) } \\
\hline$<7$ days & $13(29)$ \\
\hline$\geq 7$ days & $31(71)$ \\
\hline \multicolumn{2}{|c|}{ * MERS: Middle East respiratory syndrome } \\
\hline $\begin{array}{l}*^{* *} \text { Non-Saudi: Phil } \\
\text { ECMO: Extraco }\end{array}$ & Syrian and Jordanian \\
\hline
\end{tabular}


Table II. Risk factors for death from MERS.

\begin{tabular}{|c|c|c|c|}
\hline Characteristic & $\begin{array}{l}\text { Number }(\%) \text { of MERS } \\
\text { patients who died }(n=47)\end{array}$ & $\begin{array}{l}\text { Number (\%) of MERS patients } \\
\text { who survived }(n=56)\end{array}$ & P value \\
\hline \multicolumn{4}{|l|}{ Age (years) } \\
\hline $20-39$ & $6(25)$ & $18(75)$ & 0.0125 \\
\hline $40-59$ & $18(42)$ & $25(58)$ & \\
\hline $60-79$ & $17(59)$ & $12(41)$ & \\
\hline $80-99$ & $6(86)$ & $1(14)$ & \\
\hline \multicolumn{4}{|l|}{ Sex } \\
\hline Male & $28(48)$ & $30(52)$ & 0.4035 \\
\hline Female & $10(39)$ & $16(61)$ & \\
\hline \multicolumn{4}{|l|}{ Type of case } \\
\hline Primary & $10(59)$ & $7(41)$ & 0.4133 \\
\hline Secondary & $25(41)$ & $36(59)$ & \\
\hline Unknown & $3(50)$ & $3(50)$ & \\
\hline \multicolumn{4}{|l|}{ Nationality } \\
\hline Saudi & $34(56)$ & $27(44)$ & 0.0016 \\
\hline Non-Saudi $^{* *}$ & $4(17)$ & $19(83)$ & \\
\hline \multicolumn{4}{|l|}{ Comorbidity ${ }^{\S}$} \\
\hline Present & $34(56)$ & $27(44)$ & 0.0016 \\
\hline Absent & $4(17)$ & $19(83)$ & \\
\hline \multicolumn{4}{|c|}{ Patient on ECMO } \\
\hline Yes & $9(90)$ & $1(10)$ & $0.0030^{Ð}$ \\
\hline No & $38(41)$ & $55(59)$ & \\
\hline \multicolumn{4}{|c|}{ Contact with MERS case } \\
\hline Yes & $22(43)$ & $29(57)$ & 0.5413 \\
\hline No & $16(49)$ & $17(51)$ & \\
\hline \multicolumn{4}{|c|}{ Contact with camel } \\
\hline Yes & $19(56)$ & $15(44)$ & 0.1426 \\
\hline No & $28(41)$ & $41(59)$ & \\
\hline
\end{tabular}

* MERS: Middle East respiratory syndrome

** Non-Saudi: Philippine, Indian, Egyptian, Bangladeshi, Pakistani, Sudanese, Syrian and Jordanian Comorbidity: Associated conditions like diabetes mellitus, hypertension, ischemic heart disease, obesity, smoker, renal disease

§ ECMO: Extracorporeal membrane oxygenation ${ }^{\oplus}$ Fishers exact $p$ value 


\section{Discussion and Conclusion}

The study highlights older age, nationality, ECMO treatment, and associated comorbid conditions as probable risk factors for poor outcomes. Excluding health care workers (21\% of the cases), the majority of patients were elderly. The mortality rate was distinctly higher in patients aged $>60$ years in our study, compared to previous studies. ${ }^{6}$ Systematic reviews have strongly linked associated comorbidities with poorer outcomes. ${ }^{7}$ Male sex was not a risk factor for death, which was not in agreement with findings from other studies. ${ }^{7}$ Though not statistically significant in our study, relationship between exposure to camels and MERS has been reported to be strong. Being a Saudi national was strongly associated with death, similar to Aleanizy et al. ${ }^{8}$ Though the reasons for this association are yet unclear; cultural issues and the intimacy of the people with camels might be a plausible area of exploration (personal communication).

Our study has few limitations. It was out of scope to capture cultural and personal behavior of the patients. We did not analyze the extent and type of contact with camels or camel products, which may have impacted study outcomes.

The occupational profiles of the patients need exploration. More than $50 \%$ of patients who died were involved in occupations with close contact with camels, camel products, or probable MERS-infected patients. The list of job profiles can be considered in designing cost-effective interventions for prevention, early detection and timely management.

Ninety percent patients on ECMO died, in agreement with findings from a study by AI Ghamdi et al., ${ }^{9}$ indicating that severity of illness at admission prognosticates poor outcomes irrespective of age. Overall mortality was higher in patients aged $>60$ years, but patients on ECMO were 41 years on average. There was no evidence of treatment delay in these cases. Patients with compromised lung capacity, ECMO treatment, the elderly, and those with associated comorbidities showed adverse outcomes as shown in other studies too. ${ }^{10}$ Among patients who died, $90 \%$ had comorbidities, suggesting possible immunosuppressive state and susceptibility to infections. Information about the treatment modalities of the patients was not collected.
The above-mentioned risk factors need to be considered in patient management and necessary modifications adopted. A strong surveillance system for early identification of cases may help save lives. Infection control practices in hospitals need to be strengthened for early detection and effective management, to help prevent occurrence of cases among health care providers and further spread leading to nosocomial outbreaks.

\section{Ethics approval}

National program data were used in this study; no individual patient consents were obtained. Necessary approval for using the data was obtained from the Directorate of Health Affairs, Al Ahsa, Saudi Arabia.

\section{Acknowledgements}

We are grateful to the Al Ahsa Command and Control Centre, Directorate of Health Affairs, Saudi Arabia, for allowing us to access the national program data.

\section{Conflicts of interest:}

None.

Funding

None.

\section{References}

1. WHO. Middle East respiratory syndrome coronavirus (MERSCoV).http://www.who.int/emergencies/mers-cov/en/ [Accessed January 21, 2020]

2. WHO MERS-CoV Global Summary and risk assessment, 5 December 2016, WHO/MERS/RA/16.1. http://www.who. int/emergencies/mers-cov/mers-summary-2016.pdf?ua=1 [Accessed January 21, 2020]

3. Health Statistics Annual Book, Kingdom of Saudi Arabia, 2015. https:/www.moh.gov.sa/en/Ministry/Statistics/book/ Documents/StatisticalBook-1436.pdf [Accessed January 21, 2020]

4. Ministry of Health. Case definition and surveillance guidance - updated June 2015. http://www.moh.gov.sa/en/CCC/ Regulations/Case\%20Definition.pdf [Accessed January 21, 2020]

5. Saad M, Omrani AS, Baig K, et al. Clinical aspects and outcomes of 70 patients with Middle East respiratory syndrome coronavirus infection: a single-center experience in Saudi Arabia. Int J Infect Dis 2014; 29: 301-306. https://doi. org/10.1016/j.ijid.2014.09.003

6. Matsuyama R, Nishiura H, Kutsuna S, Hayakawa K, Ohmagari $\mathrm{N}$. Clinical determinants of the severity of Middle East respiratory syndrome (MERS): a systematic review and metaanalysis. BMC Public Health 2016; 16: 1203. https://doi. org/10.1186/s12889-016-3881-4 
7. Memish ZA, Cotton M, Meyer B, et al. Human Infection with MERS Coronavirus after Exposure to Infected Camels, Saudi Arabia, 2013. Emer Infect Dis 2014; 20(6): 1012-1015. https:// doi.org/10.3201/eid2006.140402

8. Aleanizy FS, Mohmed N, Alqahtani FY, Mohamed R. Outbreak of Middle East respiratory syndrome coronavirus in Saudi Arabia: a retrospective study. BMC Infect Dis 2017; 17: 23. https://doi.org/10.1186/s12879-016-2137-3

9. Mohammed AG, Alghamdi KM, Ghandoora Y, et al. Treatment outcomes for patients with Middle Eastern Respiratory Syndrome Coronavirus (MERS CoV) infection at a coronavirus referral center in the Kingdom of Saudi Arabia. BMC Infect Dis 2016; 16: 174. https://doi.org/10.1186/s12879-016-1492-4

10. Rozencwajg S, Pilcher D, Combes A, Schmidt M. Outcomes and survival prediction models for severe adult acute respiratory distress syndrome treated with extracorporeal membrane oxygenation. Crit Care 2016; 20: 392. https://doi. org/10.1186/s13054-016-1568-y 